\title{
The role of empathy in preparing teachers to tackle bullying
}

\author{
Helena Murphy ${ }^{1 *}$ (D), John Tubritt² (D), James O'Higgins Norman³ (D) \\ ${ }^{1}$ National Anti-Bullying Research and Resource Centre, Institute of Education, Dublin City University, \\ Ireland \{helena.murphy@dcu.ie\} \\ ${ }^{2}$ National Anti-Bullying Research and Resource Centre, Institute of Education, Dublin City University, \\ Ireland \{john.tubritt2@mail.dcu.ie\} \\ ${ }^{3}$ National Anti-Bullying Research and Resource Centre, Institute of Education, Dublin City University, \\ Ireland \{james.ohigginsnorman@dcu.ie\} \\ Received on 18 August 2017; revised on 16 November 2017; accepted on 27 November 2017; published on 15 January 2018
}

\begin{abstract}
Much research on bullying behaviour in schools among students has been carried out since the 1970's, when Olweus started a large-scale project in Norway which is now generally regarded as the first scientific study on bullying. Yet, there has been little research on how teachers respond to reports of bullying and tackle bullying behaviour in post-primary schools. This paper reports on a preliminary study investigating teacher empathy levels and their preparedness for tackling bullying in a post-primary school in Ireland. There were two research questions central to this research. The first looked at how empathic are teachers in this school? The second examined to what extent it prepares them for tackling bullying? In answering these questions we relied on the Interpersonal Reactivity Index (IRI) to gather data on empathy levels among teachers $(n=10)$, with findings related to existing research in the field. The results showed that teacher empathy is an important factor in creating and maintaining a positive school climate, which in turn leads to a prevention of bullying situations.
\end{abstract}

\section{KEYWORDS: EMPATHY, TEACHERS, BULLYING}

\section{INTRODUCTION}

The following preliminary study will investigate how teacher empathy levels relate to their ability to create a positive school climate and tackle bullying behaviour. Empathy is negatively associated with aggressive actions such as bullying (Davis, 1996; Noorden van, Haselager, Cillessen, \& Bukowski, 2015). Teachers can cultivate students' successful holistic development by promoting prosocial values, and an ethos of respect and equality in the classroom. High levels of empathy and developed prosocial skills result in an awareness and acceptance of others (Sullivan, Cleary, $\&$ Sullivan, 2003). Young people are rarely bullied because of their sameness, rather it is because of their differences to their

*To whom correspondence should be addressed: peers, even if these differences are positive. O'Higgins Norman (2008) promotes educating our children to the fact that diversity is a 'normal' part of life.

Bullying behaviour can occur in any organisation and over a prolonged period of time has been identified as a social phenomenon that causes significant concern in society (O'Higgins Norman \& Sullivan, 2017; Stassen Berger, 2006). Bullying behaviour can be evident in a number of ways ranging from physical abuse to teasing or exclusion from a group. The need that children have to belong to a group, to experience social power and to develop and maintain friendships, is all factors that underpin bullying behaviour (Macklem, 2003). As a result of this need to fit in socially, Lereya et al. (2015) reported that being bullied by peers had more detrimental effects on young adult's mental health than being victimised by adults.

Teachers not only educate, but also have a duty of care for their students. Glendenning (2012) notes that:

It is well settled that a teacher or school authority owes a duty of care to his or her pupils which may arise from the fact that parents have entrusted their children to the care and control of the school (p.462).

Consequently, it is important that teachers are aware of the signs of bullying and have the ability to tackle it at the earliest stage.

However, we argue that despite a well-established legal duty of care in the teaching profession, caring for students in schools requires more than a legal obligation. In fact, realising their duty of care requires teachers who are empathic, with specific competencies to consider the pastoral needs of their students and to respond to them appropriately. This paper will specifically examine how teacher empathy levels can play a role in recognising and tackling bullying in schools. The assistance and training that teachers require in order to deal with bullying in schools will also be examined. The results section will give a detailed breakdown of the findings of data collected from teachers in the researched school. 


\subsection{Theoretical Framework}

The framework of the research to be undertaken to explore the relationship between teacher empathy, school culture and bullying in the researched school will be achieved through a review of the literature in the field. There will be discussion on the effects of bullying behaviour, as well as an examination of the literature from National and International experts on bullying such as O'Moore and Olweus among others. An examination of Empathy and Caring from experts such as Davis and Cooper will be considered in relation to Bandura's 'Social Learning Theory' (Bandura, 1937) which explains that all behaviour is learned from the people we interact with.

\subsection{Literature Review}

The effects of bullying can be long term and detrimental to health and well-being (O'Moore, 2012). Lasting consequences such as a higher risk of developing, depression, anxiety disorders and or an antisocial personality, along with a decreased educational and occupational attainment and an increased risk of illegal behaviour and substance abuse, are all possible variables of engaging in bullying behaviour (DES, 2013). Regardless of whether bullying takes place face-to-face or online, those who are bullies, victims, or bystanders can be equally negatively affected by participating in, or witnessing bullying behaviour (O'Moore, 2010; Olweus, 1993). In Ireland, the Department of Education and Skills (DES) Anti-Bullying Procedures for Primary and Post Primary Schools (2013), define bullying as:

Unwanted negative behaviour, verbal, psychological or physical conducted by an individual or group against another person (or persons) and which is repeated over time (p. 8).

A number of factors have been found to encourage children to bully in schools such as; inconsistent and inflexible rules, punishment that is too harsh, abusive, or humiliating, and inadequate supervision (O'Moore, 2013). There is much to be gained both in an human and academic vein by including themes of care in the curriculum (Noddings, 2007). Teachers with empathy have a strong moral concern for pupils, and over time, form deeper relationships which build pupils self-esteem and self-worth. This teacher-pupil relationship also creates emotional bonds which establish trust, generating a safe and secure classroom environment and promote empathy among students.

Findings from 543 teachers from Israel suggest that empathic teachers were found to possess a higher level of morality and excellent communication with students which in turn encourages empathic peer relationships and the successful motivation of their students (Goroshit \& Hen, 2016). Teachers can create an environment which will nurture the moral development of students within the classroom thus promoting empathy and reducing the likelihood of bullying behaviour (Jevtic, 2014). Batanova and Loukas (2011) find that students who scored high on the 'empathic concern' scale also had low levels of aggression.

Davis (1996) explains empathy as:

"A set of constructs having to do with the responses of one individual, to the experiences of another. These constructs specifically include the processes taking place within the observer and the affective and non-affective outcomes which result from those processes" (p.12).

Displaying empathic tendencies depends greatly on the individual, the contextual situation, and the environment - both macro and micro. Observers bring certain characteristics to an episode, which have the potential to influence both processes and outcomes. The capacity for empathy, the previous socialisation of empathy related values and individual differences are all factors which produce effects on empathic behaviour (Davis, 1996).

Caring teachers will view their role as not only to provide for the pupils academic development but also to assist students to acquire moral habits which are essential for respectful classroom behaviours and which are productive for independent living and contributing to their community. Social problems in the classroom, such as bullying, are of a moral nature (Jevtić, 2014). Pupils want caring adults to guide them and teach them how to negotiate life's challenges (Fink, 2007). Teacher empathy is crucial for the development of students' values, motivation and achievement, impacting society in a micro and macro sense (Cooper, 2011). Empathy is described as "the glue that binds us together in functioning, beneficial families, communities and countries" Bazalgette (2017 introduction, para. 3). Fundamentally, from a social perspective, empathy draws us to help others and stops us from hurting others (Baron-Cohen \& Wheelwright, 2004). Children coming from close and secure family relationships display empathy by showing affective responses to the experiences of others (Davis, 1996). Children with lower levels of empathy find the social interaction of the classroom challenging, and can be particularly difficult for teachers to support, yet, require the most empathy from teachers (Cooper, 2004).

Successful teachers require 'fundamental empathy' which Cooper (2004) describes as the basic characteristics and skills of communication which are necessary to commence empathic teacher-pupil relationships. The development of empathy in teachers relies on reading pupils body language, hearing their voices, meeting their eyes and seeing facial expressions (Dolby, 2013). Empathic teachers possess a higher level of morality and excellent communication with students, which in turn encourages empathic peer relationships (Goroshit \& Hen, 2016) thus, hindering bullying behaviour. However, Bonnet, Goossens, Willemen, and Schuengel (2009) caution that teachers who rate low on empathy may not view negative interactions between children as bullying or may minimize their seriousness. Furthermore, the extent to which teachers can empathise with their students is significantly affected by issues related to their cultural capital. Teachers' beliefs about education and their students are heavily influenced by their cultural heritage and have been found to influence classroom practices. It should also be noted that teachers' beliefs about their students are an important indicator of educational achievement (O'Higgins Norman, 2011). The possibility for a clash of cultures between teachers and students is clear where teachers from bourgeois backgrounds are increasingly being asked to work with ethnic minorities and those from lower socioeconomic backgrounds. Mills and Gale (2010) warn that without access to the educative effects of the cultural capital of the dominant group (i.e. bourgeois) those from minority or marginalised populations will not succeed at school. It is clear that the relationship between teacher and pupil and the extent to which teachers can empathise with their students is closely related to both cultural capital and educational outcomes.

Bucher (1997) goes further by arguing that role models are one of the most important pedagogical agents in the history of education. The way in which pupils identities are constructed 
and shaped in the classroom are mainly as a result of the dominant discourses and the discursive practices of teachers (Major \& Santoro, 2014). Alternatively, teachers can serve as negative role models, by ignoring bullying behaviour or failing to notice its signs, and sometimes, actually bullying children themselves (Schuster \& Bogart, 2013). When teachers show acts of kindness through their words and actions, research shows that pupils will emulate the behaviour by engaging in further acts of kindness (de Souza \& McLean, 2012). This concurs with Bandura's (1937) 'Social Learning Theory' which states that the people with whom we regularly interact with, determine the types of behaviour that we will observe and emulate. The determinants of behaviour reside not within the person but in environmental forces. Behaviour is learned from the environment through the process of observational learning - it is subject to external control (Bandura, 1977). In light of this theory, it is imperative that teachers, as role models for children, are aware of the behaviour that they display and the impact it has on the children they are in contact with.

Teachers play an important role in setting classroom norms; classroom norms can have a powerful influence on whether children act on their empathy, and use their social rank to defend their peers in bullying situations (Peets, Pöyhönen, Juvonen, \& Salmivalli, 2015). Pozzoli, Gini, and Vieno (2012) concur, stating that children will adapt to the school norms, highlighting the power of peer and teacher relationships for accepting or rejecting bullying behaviour.

Hektner and Swenson (2012) and O'Higgins Norman (2008) report that teachers who believed that bullying behaviour is normative are less likely to intervene to stop bullying. This suggests some teachers lack insight and empathy sufficient enough to tackle bullying. Although some teachers understanding of bullying may be low, individual personalities must also be considered Research from Bauman and Del Rio (2006) finds that teachers had the least empathy for the victims of relational bullying over physical and verbal bullying, and were least likely to intervene in relational bullying incidents. Apart from a lack of knowledge about bullying, variations in teacher responses may also reflect teachers' a lack of empathy (Troop-Gordon \& Ladd, 2015). Teachers with empathy will take time to understand students' behaviours and manage appropriately. Waasdorp and Bradshaw (2011) recommend continuous professional development in bullying intervention strategies, for teachers to assist in tackling bullying behaviours. This is crucial for educators, as some people intrinsically have more empathy than others (Bazalgette, 2017) and as such are more prepared to tackle bullying among their students. Jevtic (2014) recommends teacher training to enhance the moral socialisation of students and advises the conduction of moral education as a separate subject in order to shape students attitudes.

Previous research demonstrates that the role of the teacher is a key factor in bullying prevention (Olweus, 1993; O'Moore, 2013). Indeed, results go some way to explaining this relationship as they show that poor teacher-pupil relationships is a factor which contributes to bullying behaviour (Harel-Fisch et al., 2011). Junger-Tas proclaims that teachers can set high standards in personal relations by way of showing their own good behaviour (as cited in Smith et al. 2000). Teachers can show good example in the hope that bad behaviour can be changed (Bandura, 1937). Social relationships with teachers are an important indicator to child self-image, with pupils who do not have trusting pupil-teacher relationships or with pupils who have discipline problems having more negative self-evaluations (Williams et al., 2009).

\section{METHODOLOGY}

This preliminary study examines the level of teacher empathy in a post primary school in Ireland. The purpose of this preliminary study is to assess the school's situation and decide what, if any changes need to be made. The specific questions that will be examined are how empathic are teachers in this school, and to what extent do their levels of empathy prepare them in tackling bullying?

Human experience is an important aspect of the study directly linking data gathered from surveys to the hypothesis. Due to the positivist nature of the research, this study adopts a deductive approach which involves developing a hypothesis: how empathic are teachers in this school and to what extent do their levels of empathy prepare them in tackling bullying and testing it based on existing theory, and a research strategy (Wilson, 2010). This approach may be viewed as the most familiar assessment of the relationship between theory and research and results acquired from this approach are developed through logical reasoning (Bryman \& Bell, 2007). Analysis of data will be compared to existing literature.

\subsection{Materials}

The Interpersonal Reactivity Index (IRI) (Davis, 1983) (Appendix A) was developed to provide a multidimensional approach to measuring empathy, under four separate constructs in a seven item subscale. There are a total of 28 questions, 7 for each construct of Perspective Taking (PT), Fantasy Scale (FS), Empathic Concern (EC), and Personal Distress (PD) on a 5-point Likert scale ranging from "Does not describe me well" to "Describes me very well". The IRI was completed by teachers $(n=10)$. Davis' IRI has proven to be appropriate for measuring the expression of empathy in social relationships such as those between teachers and students (Warren, 2015b). This scale from the field of social psychology is widely used to measure empathy in disciplines such as nursing and teaching (Hojat et al., 2005; Tettegah and Anderson, 2007). Davis (1980) suggests that empathy is a complex multidimensional concept and the qualities measured can only be assessed separately: a) the Cognitive Dimensions which are the perspective taking capabilities of the individual and b) the Emotional Dimensions which are explained as the emotional reactivity of individuals. The scale measures two Cognitive Dimensions: Perspective Taking (PT) and Fantasy Scale (FS) and two Emotional Dimensions: Empathic Concern (EC) and Personal Distress (PD).

PT is explained as experiencing emotions in relation to emotions felt by others. PT is an effortless action. It is also an advanced cognitive process. PT means suppressing one's own perspective on events and actively entertaining someone else's view of the situation. PT can also be described as 'role taking' or 'cognitive empathy'. The PT scale focuses the measure on the person's perspective taking tendencies in different situations, rather than the person's perspective taking ability or capacity. 'I try to look at everyone's side of a disagreement before making a decision'. PT abilities allow us to make more informed assessments of situations by seeing things from another's point of view.

FS measures the tendency to imaginatively transpose oneself into fictional situations. FS is related to the ability to identify oneself with characters in movies, novels, and plays. 'After seeing a play or movie I have felt as though I was one of the characters.' It is also known as imaginative empathy. As with PT, the scale appears to be in the role taking category, however it is complicated as all questions relating to FS are regarding fictional characters 
(Davis, 1996). However, research from Nomura \& Akai (2012) finds that empathy for real people and empathy for fictional characters is similar, suggesting that FS is similar to PT.

$\mathrm{EC}$ is an emotional dimension of the IRI. EC assesses the respondent's chronic emotional reactions to the negative experiences of others, measuring respondents' feelings of warmth, compassion, and concern for unfortunate others. 'I often have tender, concerned feeling for people less fortunate than me.' EC values the welfare of the person in need.

PD measures self-oriented feelings of personal anxiety in tense interpersonal settings. It assesses the personal feelings of anxiety and discomfort that occur from observing another's negative experience. The emotional state which leads to helping others is a depressed mood state, characterised by feelings of sadness and dejection, whereas experiencing a state of emotional arousal with clear distress/anxiety is unlikely to produce greater helping. 'When I see someone who badly needs help in an emergency, I go to pieces.' (Davis, 1996).

\section{RESULTS}

This survey was completed by teachers $(n=10)$ in order to examine their empathy levels. The purpose of this is to examine how empathic teachers in this school are, and to what extent does it prepare them for tackling bullying (see Table 1)

The IRI tapped into four different aspects of teacher's empathy, PT, FS, EC and PD. PT measures cognitive dimensions. Table 1 shows that the mean score for PT is 16.8 and the standard deviation is 4.6, indicating that most participants' scores are close to the mean score. Respondent no. 3 has the highest score possible in
Perspective Taking at 28, and is considered an outlier as this score is at an abnormal distance from other values in the scale (fig 4.9). With the exception of the outlier of 28 , the range is 7 , showing that perspective taking is generally quite similar for respondents. A mean of 16.8 is higher than the average score on the scale to 28 , showing that overall the teachers empathy levels are slightly higher than average on the scale (see Table 2).

FS measures the tendency to get caught up in fictional stories and imagine oneself in the same situations as fictional characters. This construct of the scale measures cognitive dimensions. The mean score is 15.7 with a median of 16 , and the standard deviation is 5.9 indicating that the scores are spread out over a range of values (Table 1) with 4 out of 10 teachers under the mean and 6 teachers above (see Table 3).

EC, also known as 'emotional empathy', measures concern for others. This construct of the scale measures emotional dimensions. The mean score for Empathic Concern is 16.5 (Table 1). The standard deviation is low at 4.7. Apart from the outlier of 28 , the range is between 10 and 19 with a value of 9 , which suggests that the teachers have similar scores for Empathic Concern (see Table 4).

PD measures the emotions that hinder helping others. This scale has the lowest mean (12.3) of the four subscales (Table 1). This construct of the scale measures emotional dimensions. The standard deviation is also high which suggests that the scores are widespread. Excluding the outlier of 28, the range is 13. Seven of the scores are below the mean which would indicate that these teachers have a tendency to experience a lower level of personal distress in stressful situations. Excluding outlier no. 3, only two teachers are above the mean, suggesting that they may find tackling bullying behaviour distressing (see Table 5).

Table 1. IRI participants scores

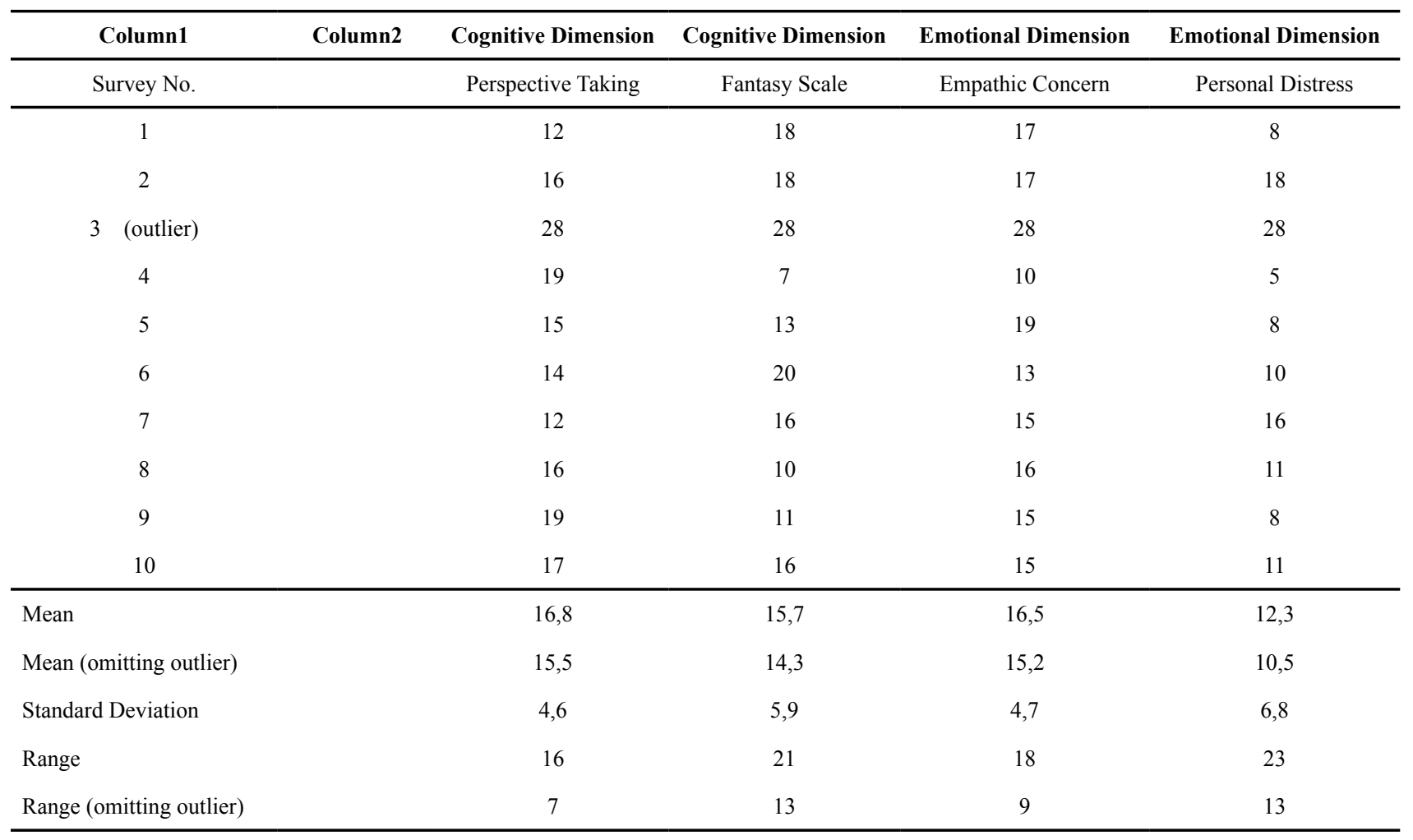


Table 2. Rank order low to high (perspective taking)

\begin{tabular}{cc}
\hline Survey No. & Score \\
\hline 1 & 12 Quartile \\
7 & 12 Range \\
6 & 14 \\
5 & 15 \\
2 & 16 (median) \\
8 & 16 \\
10 & 17 \\
4 & 19 Quartile \\
9 & 19 Range \\
3 & 28 (outlier) \\
\hline
\end{tabular}

Table 3. Rank order low to high (fantasy scale)

\begin{tabular}{cc}
\hline Survey No. & Teacher Score \\
\hline 4 & 7 Quartile \\
8 & 10 Range \\
9 & 11 \\
5 & 13 \\
7 & 16 (median) \\
10 & 16 \\
1 & 18 \\
2 & 18 \\
6 & 20 Quartile \\
3 & 28 Range \\
\hline
\end{tabular}

Table 4. Rank order low to high (empathic concern)

\begin{tabular}{cc}
\hline Survey No. & Teacher Score \\
\hline 4 & 10 \\
6 & 13 \\
& \\
7 & 15 \\
9 & 15 \\
10 & $($ median 15.5$)$ \\
8 & 16 \\
1 & 17 \\
2 & 17
\end{tabular}

Table 5. Rank order low to high (personal distress)

\begin{tabular}{cc}
\hline Survey No. & Teacher Score \\
\hline 4 & 5 \\
1 & 8 \\
5 & 8 \\
9 & 8 \\
6 & 10 (median 10.5) \\
8 & 11 \\
10 & 11 \\
7 & 16 \\
2 & 18 \\
3 & 28 (outlier) \\
\hline
\end{tabular}

\section{DISCUSSION AND CONCLUSIONS}

The school is one of the first important social institutions directly experienced by children, as such, everyday interactions and experiences in the classroom, can shape children's view of the world and how they develop. The teacher is a significant catalyst among others in enabling the school to address urgent social issues like equality, changing sexual mores, racism and bullying (O'Higgins Norman, 2014). It is imperative that students witness teachers addressing all bullying behaviour, in order to have confidence that their reports of bullying will not go unheard, reinforcing a positive school climate.

Findings from the study show that teachers' empathy levels are higher than average on the subscales for PT, EC and FS, while results on the PD scale are on the lower end of the scale. With regard to the former three subscales, the scores suggest that overall teachers have levels of empathy to be prepared to tackle bullying behaviour as their results suggest that they are capable of taking another's perspective and feeling concern. The teachers' low score on the PD subscale is necessary if teachers are to tackle bullying, as PD represents emotions that hinder helping others in stressful situations. Davis (1980) explains the PD subscale as measuring self-oriented feelings of personal anxiety in tense interpersonal settings. A high score in PD would suggest that teachers experience some distress when witnessing bullying situations, this anxious state, would suggest low levels of competence in tackling bullying behaviour. Craig, Henderson and Murphy (2000) state that teachers who express empathy for others, are more likely to identify bullying, report it, and intervene. Perspective Taking (PT) assesses the process of social role taking (Davis, 1996). This is an important element in tackling bullying as teachers need to be able to assess situations by taking both the perspective of the alleged victim and bully, in order to come to a conclusion regarding the behaviour. PT is generally quite similar for respondents with a range of 7, with the exception of respondent no. 3 with the highest possible score across all 4 constructs (outlier of 28) see (Table 1). The Fantasy Scale measures the tendency to get caught up in fictional stories and imagine oneself in the same situations as fictional characters. It is also known as imaginative empathy. As 
with PT, the scale appears to be in the role taking category, however it is complicated as all questions relating to FS are regarding fictional characters (Davis, 1996). Empathic Concern (EC) scale measures emotional empathy or concern for others. EC assesses our 'imagine-the-other' levels (Davis, 1996). This construct scores second highest, with teachers scoring higher than average on the scale. This element of empathy is important for teachers to care enough about addressing bullying situations. EC is the ability to understand how students feel and take reports of bullying seriously.

A fundamental mistake teachers can make in tackling bullying behaviour is in choosing the bullying incidents which they perceive to be necessary for teacher intervention, believing that some incidents are minimal and the victim involved will over it easily. Setting a precedence of this nature is dangerous, as some pupils simply do not have the emotional tools to put the incident behind them, thus, a lack of support from the teacher may have the effect of heightening their sense of isolation and rejection, causing them extensive emotional damage (O'Moore, 2013). Values are transmitted in an unacknowledged way through the life of the school (Carr \& Landon, 1999). A mean of 16.8 (Table 1) shows that overall the teachers levels of are slightly higher than average on the scale. This score suggests that, generally, these teachers can adopt a student's point-of-view, understanding the students' perspective. Empathic teachers are aware of their students' holistic requirements and strive to meet them by demonstrating their own empathic behaviour. Teacher's behaviour and value system impacts students, as it is not only explicit learning that is taught but implicit too (Bucher, 2008). In order to create a safe learning environment for pupils, it is imperative that teachers challenge all aggressive acts and ensure no level of bullying behaviour is ignored, thus instilling confidence in pupils' belief in the teacher's ability to tackle bullying behaviour (O’Moore, 2010). Teachers' awareness of their interactions with all pupils is necessary in order to provide all pupils with a sense of connectedness in the daily school experience. This can be accomplished through positive teacher and peer relationships, which, will ultimately lead to a decrease in bullying behaviour (Harel-Fisch et al., 2011).

There are several limitations to the study, the main limitation is that, as a preliminary study, only quantitative data was gathered from one school, and as such, conclusions cannot be generalised. A larger scale case study, collecting both qualitative and quantitative data from teachers and students would be more representative. Qualitative data in the form of interviews or observation would have been beneficial for triangulation of data. However, as a preliminary study, the research reported gives us an insight into how one school measures up in terms of teachers' empathy levels. It is evident from the literature reviewed that teacher empathy is an important factor in both intervention and prevention in tackling bullying situations. The necessity for teachers to care about the holistic well-being of students is paramount in ensuring a positive school climate, limiting bullying behaviour.

\section{REFERENCES}

Baron-Cohen, S., \& Wheelwright, S. (2004). The empathy quotient: An investigation of adults with asperger syndrome or high functioning autism, and normal sex differences. Journal of Autism and Developmental Disorders, 34(2), 163-175. doi:10.1023/B:JADD.0000022607.19833.00

Batanova, M. D., \& Loukas, A. (2011). Social anxiety and aggression in early adolescents: Examining the moderating roles of empathic concern and perspective taking. Journal of Youth and Adolescence, 40(11), 1534-1543. doi:10.1007/ s10964-011-9634-x

Bazalgette, P. (2017). The empathy instinct: How to create a more civil society. London: John Murray Publishers.
Bonnet, M., Goossens, F. A., Willemen, A. M., \& Schuengel, C. (2009). Peer victimization in Dutch school classes of four- to five-year olds: Contributing factors at the school level. The Elementary School Journal, 110(2), 163-177. doi: $10.1086 / 605769$

Bucher, A. A. (1997). The influence of models in forming moral identity. International Journal of Educational Research, 27, 619-627. doi:10.1016/S08830355(97)00058-X

Carr, D. and Landon, J. (1999). Teachers and schools as agencies of values education: Reflections on teachers' perceptions. Part Two: the hidden curriculum. Journal of Beliefs and Values, 20(1), 21-29. doi:10.1080/1361767990200102

Collins, H. (2010). Creative research: The theory and practice of research for the creative industries. Switzerland: AVA Publications.

Cooper, B. (2004). Empathy, interaction and caring: Teachers' roles in a constrained environment. Pastoral Care in Education, 22(3), 12-21. doi:10.1111/ j.0264-3944.2004.00299.x

Cooper, B. (2011). Empathy in education: Engagement, values and achievement. London: Continuum International Publishing Group.

Craig, W., Henderson, K., \& Murphy, J. (2000). Prospective teachers' attitudes toward bullying and victimization. School Psychology International, 21 (1), 5-21. doi: $10.1177 / 0143034300211001$

Department of Education and Skills (2013). Anti-Bullying procedures for primary and post primary schools. Retrieved from https://www.education.ie/en/Publications/Policy-Reports/Anti-Bullying-Procedures-for-Primary-and-Post-Primary-Schools.pdf

Davis, M. H. (1983). Measuring individual differences in empathy: Evidence for a multidimensional approach. Journal of Personality and Social Psychology, 44(1), 113-126. doi:10.1037/0022-3514.44.1.113

Davis, M.H. 1996. Empathy. A social psychological approach. USA: Westview Press.

De Souza, M., \& McLean, K. (2012). Bullying and violence: changing an act of disconnectedness into an act of kindness. Pastoral Care in Education: An International Journal of Personal, Social and Emotional Development, 30(2), 165-180. doi:10.1080/02643944.2012.679955

Dolby, N. (2013). The decline of empathy and the future of liberal education. Liberal Education 60-64.

Fink, J. 2007. Caring: At the heart of an educator's role. Retrieved from http://www.character.org/uploads/PDFs/Misc_/Kristie's_Article.pdf

Glendenning, D. (2012). Education and the law. London: Bloomsbury.

Goroshit, M., \& Hen, M. (2016). Teachers' empathy: can it be predicted by self-efficacy? Teachers and Teaching: Theory and Practice, 22(7), 805-818. doi:10.1080/13540602.2016.1185818

Harel-Fisch, Y., Walsh, S. D., Fogel-Grinvald, H., Amitai, G., Pickett, W., Molcho, M., Due, P., Gaspar de Matos, M., \& Craig, W. (2011). Negative school perceptions and involvement in school bullying: A universal relationship across 40 countries. Journal of Adolescence, 34, 639-652. doi:10.1016/j.adolescence.2010.09.008

Hektner, J. M., \& Swenson, C. A. (2012). Links from teacher beliefs to peer victimization and bystander intervention: Tests of mediating processes. Journal of Early Adolescence, 32, 516-536. doi:10.1177/0272431611402502

Hojat, M., Mangione, S., Nasca, T. J., Gonnella, J. S., \& Magee, M. (2005). Empathy scores in medical school and ratings of empathic behavior in residency training 3 years later. The Journal of Social Psychology, 145(6), 663-672.doi:10.3200/ SOCP.145.6.663-672

Jevtic, B. (2014). Teachers' pedagogical actions affecting the moral development of personality. Problems of Education in the 21st Century, 58, 67-81.

Lereya, S. T., Copeland, W. E., Costello, E. J., \& Wolke, D. (2015). Adult mental health consequences of peer bullying and maltreatment in childhood: two cohorts in two countries. The Lancet Psychiatry, 2(6), 524-531. doi:10.1016/S2215-0366(15)00165-0

Macklem, G. L. (2003). Bullying and teasing: social power in children's groups. New York: Kluwer Academic/Plenum Publishers. doi:10.1007/978-1-47573797-4

Major, J., \& Santoro, N. (2014). 'Sensible girls' and 'silly boys': what do teachers need to know about gender? The Australian Educational Researcher, 41(1), 5972. doi:10.1007/s13384-013-0121-0

Mills, C., \& Gale, T. (2010). Schooling in Disadvantaged Communities Playing the Game from the Back of the Field. Springer.

Noddings, N. 2007. Teaching Themes of Care. Retrieved from http://www.bu.edu/ ccsr/files/2011/04/Spring-2007.pdf.

Noorden van, T. H. J., Haselager, G. J. T., Cillessen, A. H. N., \& Bukowski, W. M. (2015). Empathy and involvement in bullying in children and adolescents: A systematic review. Journal of Youth and Adolescence, 44(3), 637-657. doi:10.1007/ s10964-014-0135-6

Nomura, K., \& Akai, S. (2012). Empathy with fictional stories: reconsideration of the fantasy scale of the interpersonal reactivity index. Psychological Reports, 110(1), 304-314. doi:10.2466/02.07.09.11.PR0.110.1.304-314

Olweus, D. (1993). Bullying at school: What we know and what we can do. Oxford: Blackwell. 
O'Higgins Norman, J. (2008). Homophobic bullying in Irish secondary schools. Paulo Alto: Academica Press.

O'Higgins Norman, J. (2008). Tackling bullying and discrimination: A whole school approach. Retrieved from https://www.education.ie/en/Press-Events/ Events/cp_anti_bullying/Anti-Bullying-Forum-Submissions/anti_bully_sub_ academic_dr_ohiggins_norman.pdf

O'Higgins Norman, J. (2010). School principals need to take action to combat homophobic bullying. Irish Human Rights and Equality Commission. Retrieved from http://www.ihrec.ie/news/2010/11/23/school-principals-need-to-take-action-to-combat-ho/

O'Higgins Norman, J. (2011). Sociology of education in: Education Studies in Ireland. Dublin: Gill and McMillan.

O’Higgins, N, J., \& Sullivan, K. (2017). Bullying. In Luanna Meyer (Ed), Oxford Bibliogrphies in Education. Oxford: Oxford University Press.

O' Moore, M. (2010). Understanding school bullying, a guide for parents and teachers. Dublin: Veritas.

O'Moore, M. (2012). Anti-bullying forum, Department of Education and Skills, Bullying at School: The Way Forward. Retrieved from https://www.education. ie/en/Press-Events/Conferences/cp_anti_bullying/Speech-by-Professor-MonaO-Moore.pdf

O'Moore, M. (2013). The role of guidance counsellors in developing and implementing the whole school community approach in tackling bullying, both traditional and cyber. National Centre for Guidance in Education.

Peets, K., Pöyhönen, V., Juvonen, J., \& Salmivalli, C. (2015). Classroom norms of bullying alter the degree to which children defend in response to their affective empathy and power. Developmental Psychology, 51(7), 913-920. doi:10.1037/ a0039287

Pozzoli, T., Gini, G., \& Vieno, A. (2012). The role of individual correlates and class norms in defending and passive bystanding behaviour in bullying: A Multi-level analysis. Child Development, 83(6), 1917-1931. doi:10.1111/j.14678624.2012.01831.x

Schuster, M. A., \& Bogart, L. A. (2013). Did the ugly duckling have PTSD? Bullying, its effects, and the role of pediatricians. Journal of the American Academy of Pediatrics, 131(1), 288-291. doi:10.1542/peds.2012-3253

Smith, K., \& Morita, Y. (2000). In K. Smith., Y. Morita, J. Junger-Tas, D. Olweus, R. Catalano, R., \& P. Slee (Eds.), The Nature of School Bullying: A Cross-National Perspective. London: Routledge.

Stassen Berger, K. (2006). Update on bullying at school: Science forgotten? Science Direct, 27, 90-126.

Sullivan, K., Cleary M., \& Sullivan G. (2003). Bullying in secondary schools, What it looks like and how to manage it. London: Paul Chapman.

Tettegah, S., \& Anderson, C. J. (2007). Pre-service teachers' empathy and cognitions: Statistical analysis of text data by graphical models. Contemporary Educational Psychology, 32(1), 48-82. doi:10.1016/j.cedpsych.2006.10.010

Troop-Gordon, W., \& Ladd, G. W. (2015). Teachers' victimization-related beliefs and strategies: associations with students' aggressive behavior and peer victimization. Journal of Abnormal Child Psychology, 43(1), 45-60. doi:10.1007/ s10802-013-9840-y

Williams, J., Greene, S., Doyle, E., Harris, E., Layte, R., McCoy, S., McCrory, C., Murray, A., Nixon, E., O’Dowd, T., O'Moore, M., Quail, A., Smyth, E., Swords, L., \& Thornton, M. (2009). Growing up in Ireland, national longitudinal study of children: The Lives of 9-Year-Olds. Retrieved from http://www.esri.ie/ pubs/BKMNEXT154.pdf

Wilson, J. (2010). Essentials of Business Research: A Guide to Doing Your Research Project. SAGE Publications.

How to cite this article: Murphy, H., Tubritt, J., \& O'Higgins, J. (2017). The role of empathy in preparing teachers to tackle bullying. Journal of New Approaches in Educational Research, 7(1), 17-23. doi: 10.7821/naer.2018.1.261 